\title{
Atributos químicos do solo em áreas de produção de Banana (Musa spp.)
}

\author{
Soil chemical attributes in banana production areas (Musa spp.) \\ Atributos químicos del suelo en áreas de producción de banano (Musa spp.)
}

André Luís Pereira dos Santos

ORCID: https://orcid.org/0000-0002-1533-1748 Universidade Federal da Paraíba, Brasil E-mail: professorandre.ufpb@gmail

Manoel Alexandre Diniz Neto

ORCID: https://orcid.org/0000-0002-3190-8682 Universidade Federal da Paraíba, Brasil E-mail: diniznetto@gmail.com

Thiago de Sousa Melo

ORCID: https://orcid.org/0000-0003-1862-9571 Universidade Federal da Paraíba, Brasil E-mail: pnpdthiago@gmail.com

Maria Janaina Lira Vital

ORCID: https://orcid.org/0000-0001-7396-0940 Universidade Regional do Cariri, Brasil E-mail:maria.vital@prof.ce.gov.br

Lucas Borchartt Bandeira

ORCID: https://orcid.org/0000-0002-9098-9160 Universidade Federal da Paraíba, Brasil E-mail: lucasborchartt@yahoo.com.br

George Rodrigo Beltrão da Cruz

ORCID: https://orcid.org/0000-0002-8480-4625 Universidade Federal da Paraíba, Brasil E-mail: georgebeltrao@hotmail.com José Carlos Aguiar da Silva ORCID: https://orcid.org/0000-0002-2356-3207 Empresa Brasileira de Pesquisa Agropecuária, Brasil E-mail: jose.aguiar-silva@embrapa.br

\begin{abstract}
Resumo
O uso e manejo do solo por diferentes sistemas acarretam em alterações da qualidade física e química de seus atributos. O objetivo deste trabalho foi avaliar a qualidade de um Latossolo Vermelho Amarelo distrófico, com base nas alterações dos atributos químicos em diferentes sistemas de manejo. $\mathrm{O}$ delineamento experimental utilizado foi em blocos casualizados com fatorial $3 \times 2$ constando de três transectos na área em declividade (superior, mediana e inferior) e em cada transecto, duas profundidades para coleta de amostras de solo $(0-20 \mathrm{~cm}$ e $20-40 \mathrm{~cm})$ com três repetições. A coleta das amostras de solo indeformadas foi feita aleatoriamente e realizado as análises químicas. Foram avaliados: $\mathrm{pH}$, sódio $(\mathrm{Na}+)$, alumínio trocável $(\mathrm{Al}+3)$, cátions trocáveis $(\mathrm{K}+, \mathrm{Ca}+2 \mathrm{e} \mathrm{Mg}+2)$, fósforo disponível $(\mathrm{P})$, acidez trocável (H++Al+3), matéria orgânica (MO), Soma de bases (SB), Capacidade de Troca de Cátions (CTC) e Saturação por Alumínio (m). Na camada mais profunda do solo houve incremento nos teores de alumínio levando ao aumento da saturação por este elemento, o que levou a diminuição da saturação por bases. Quanto ao relevo da área experimental, as posições inferior e mediana encontram-se com maiores valores de acidez trocável e saturação por alumínio. Já na posição superior, os valores de soma de bases e saturação por bases são mais elevadas com menores perdas e maior incremento dos teores de matéria orgânica devido às folhas de bananeiras depositadas na superfície. A utilização de técnicas multivariadas é uma ferramenta de grande utilidade na análise de dados relacionados à atributos químicos do solo.
\end{abstract}

Palavras-chave: Musa spp; Fertilidade; Indicadores; Agroecologia.

\begin{abstract}
He use and management of the soil by different systems lead to changes in the physical and chemical quality of its attributes. The objective of this work was to evaluate the quality of a dystrophic Red Yellow Latosol, based on changes in chemical attributes in different management systems. The experimental design used was a randomized block with a $2 \times 3 \times 2$ factorial consisting of three transects in the sloping area (upper, median and lower) and in each transect, two depths for collecting soil samples $(0-20 \mathrm{~cm}$ and $20-40 \mathrm{~cm})$ with three repetitions. Undisturbed soil samples were collected at random and chemical analysis was carried out. The following were evaluated: $\mathrm{pH}$, sodium $(\mathrm{Na}+)$, exchangeable aluminum $(\mathrm{Al}+3)$, exchangeable cations $(\mathrm{K}+\mathrm{Ca}+2$ and $\mathrm{Mg}+2)$, available phosphorus $(\mathrm{P})$, exchangeable acidity $(\mathrm{H}++\mathrm{Al}+3)$, matter organic (MO), Sum of bases (SB), Cation Exchange Capacity (CTC) and Aluminum
\end{abstract}


Saturation (m). In the deepest layer of the soil there was an increase in aluminum contents, leading to an increase in saturation by this element, which led to a decrease in base saturation. As for the relief of the experimental area, the lower and median positions have higher values of exchangeable acidity and aluminum saturation. In the upper position, the base sum and base saturation values are higher with less losses and greater increase in organic matter contents due to banana leaves deposited on the surface. The use of multivariate techniques is a very useful tool in analyzing data related to soil chemical attributes.

Keywords: Musa spp; Fertility; Indicators; Agroecology.

\section{Resumen}

El uso y manejo del suelo por diferentes sistemas conlleva cambios en la calidad física y química de sus atributos. El objetivo de este trabajo fue evaluar la calidad de un Latosol rojo amarillo distrófico, basado en cambios en los atributos químicos en diferentes sistemas de manejo. El diseño experimental utilizado fue un bloque al azar con un factorial $2 \times 3 \times 2$ que consta de tres transectos en el área de pendiente (superior, mediana e inferior) y en cada transecto, dos profundidades para la recolección de muestras de suelo $(0-20 \mathrm{~cm}$ y $20-40 \mathrm{~cm})$ con tres repeticiones. Se recolectaron muestras de suelo inalterado al azar y se llevó a cabo un análisis químico. Se evaluaron los siguientes: pH, sodio ( $\mathrm{Na}$ + ), aluminio intercambiable $(\mathrm{Al}+3)$, cationes intercambiables $(\mathrm{K}+, \mathrm{Ca}+2 \mathrm{y} \mathrm{Mg}+2)$, fósforo disponible $(\mathrm{P})$, acidez intercambiable $(\mathrm{H}++\mathrm{Al}+3)$, materia orgánica $(\mathrm{MO})$, Suma de bases $(\mathrm{SB})$, Capacidad de Intercambio Catiónico (CTC) y Saturación de Aluminio (m). En la capa más profunda del suelo hubo un aumento del contenido de aluminio, lo que provocó un aumento de la saturación por este elemento, lo que provocó una disminución de la saturación de bases. En cuanto al relieve del área experimental, las posiciones inferior y mediana tienen valores más altos de acidez intercambiable y saturación de aluminio. En la posición superior, los valores de suma base y saturación básica son mayores con menores pérdidas y mayor incremento en el contenido de materia orgánica debido a las hojas de banano depositadas en la superficie. El uso de técnicas multivariadas es una herramienta muy útil para analizar datos relacionados con los atributos químicos del suelo.

Palabras clave: Musa spp; Fertilidad; Indicadores; Agroecología.

\section{Introdução}

O solo manejado da forma convencional para a implantação de culturas pode modificar seus atributos físicos, químicos e biológicos de modo que, perdas significativas podem alterar sua qualidade afetando a sustentabilidade ambiental e econômica da atividade agrícola (Niero et al., 2010). Em outra análise, a qualidade preservada desses atributos possibilita condições adequadas para o crescimento e o desenvolvimento vegetal mantendo a diversidade da fauna edáfica entre outras características de qualidade do solo (Doran \& Parkin, 1994). Essas alterações no solo modificam sua estrutura e atividade da fauna edáfica, bem como sua fertilidade, com implicações direta nos agroecossistemas presentes, (Bilibio et al., 2010 \& Carneiro et al., 2009).

Portanto é preciso compreender e entender os impactos do uso e manejo do solo na forma convencional e assim desenvolver sistemas agrícolas mais sustentáveis (Bavoso et al., 2010). Os níveis de alterações na qualidade do solo podem ser estudados avaliando determinados atributos em comparação com o estado natural do solo, sem interferência antrópica, ou com valores considerados ideais (Bilibio et al., 2010).

Através dos indicadores de fertilidade do solo, que são representados por atributos químicos que apresentam relevância para os estudos agronômicos e ambientais. Quando esses atributos incidem nas características que indicam processos do solo ou de seu comportamento, capacidade de resistir à troca de cátions, necessidades nutricionais de plantas e contaminação ou poluição ambiental tornam-se bastante relevante (GomeS \& Filizola, 2006).

Os diferentes tipos de manejos agrícola, em geral, ocasionam a quebra dos ciclos biogeoquímicos no solo, pois estes podem causar impactos nas características biológicas, físicas e químicas dos mesmos. (Lazzaretti et al., 2019). As condições físicas do solo como agregação e estabilidade de agregados, textura, grau de floculação de argila, densidade do solo e porosidade também são de suma importância, pois influenciam no crescimento e desenvolvimento do sistema radicular das plantas e na capacidade de infiltração de água no solo e consequentemente, o solo se torna mais resistente ao processo erosivo e a degradação (Borchartt, 2013; Brandão et al., 2006 \& Costa et al., 2004). Rampim et al., (2020) ficaram evidentes os efeitos positivos da adoção de mais de um método de manejo, modificando os atributos físicos, como menor densidade do solo e resistência a penetração, e maior macroporosidade, aprimorando a qualidade do solo, com reduzida interferência na produtividade agrícola. 
Outra forma de monitorar a qualidade do solo é pela determinação dos teores de matéria orgânica e das frações húmicas presente no solo. Sabe-se que a matéria orgânica do solo é de grande importância para a melhoria dos atributos químicos e físicos do solo, além de sustentar a diversidade biológica (Borchartt, 2013 \& Santos et al., 2006). A cobertura vegetal dos solos e o manejo adotado interfere nas propriedades químicas e físicas do solo e a escolha do manejo pode alterar seu potencial produtivo (Faria et al., 2021). Monitoramento dos indicadores de fertilidade do solo possui grande importância para a preservação da qualidade do solo e da sustentabilidade do sistema agrícola e do ambiente (Lazzaretti et al., 2019). O objetivo desse trabalho foi avaliar a qualidade de um Latossolo Vermelho Amarelo distrófico, com base nas alterações dos atributos químicos, em diferentes sistemas de manejo.

\section{Metodologia}

O município de Bananeiras está localizado na microrregião do Brejo Paraibano. O termo Brejo é um termo relacionado a áreas úmidas e por isso é classificado como As' segundo Köppen (Alvares et al 2014), da encosta oriental do Planalto, com precipitação que chega a ultrapassar os $1.400 \mathrm{~mm} \mathrm{ano}^{-1}$ e altitude que atinge até mais que 600 metros. Apesar do relevo forte ondulado e montanhoso, os solos argilosos (Argissolo Vermelho Amarelo Eutrófico e Nitossolo Vermelho Eutrófico) e de boa disponibilidade de umidade, dão suporte ao cultivo da cana-de-açúcar, banana, citros, pastagem, fruteiras e culturas alimentares.

$\mathrm{O}$ trabalho foi desenvolvido numa área de bananicultura de propriedade particular apresentando declividade de aproximadamente $10 \%$. A área foi dividida em três subáreas para a realização das coletas de amostras de solo. Para tanto, foram abertas minitricncheiras de $40 \mathrm{~cm}$ de profundidade em pontos aleatórios dentro de cada subárea em zigue-zague. Foram coletadas amostras deformadas e indeformadas e acondicionadas em sacos plásticos, etiquetadas com as informações de cada tratamento e trazidas para o Laboratório de Fertilidade do Solo do Centro de Ciências Humanas, Sociais e Agrárias da Universidade Federal da Paraíba.

No laboratório, as amostras foram passadas em peneiras de $2 \mathrm{~mm}$ para a realização das análises dos atributos químicas

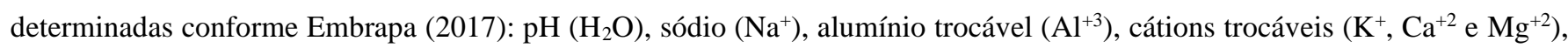
fósforo disponível (P), acidez trocável $\left(\mathrm{H}^{+}+\mathrm{Al}^{+3}\right)$, matéria orgânica (MO), Soma de bases ( $\mathrm{SB}$ ), Capacidade de Troca de Cátions (CTC), Saturação por bases (V\%) e Saturação por Alumínio (m). Foi determinado também o carbono orgânico e a matéria orgânica estimada com base nos valores do carbono orgânico.

As amostras do solo em estrutura preservada (indeformada) foram coletadas em anel volumétrico para a realização da densidade do solo (Ds) com sua relação calculada entre a massa do solo do cilindro, a massa do solo seco a $105^{\circ} \mathrm{C}$ por 24 horas e o volume do cilindro (Embrapa, 2017).

O delineamento experimental utilizado foi em blocos casualizados com fatorial $3 \times 2$ constando de três subáreas na área em declividade (superior, mediana e inferior) e em cada subárea, duas profundidades para coleta de amostras de solo $(0-20 \mathrm{~cm}$ e $20-40 \mathrm{~cm})$ com três repetições.

Na presente pesquisa foi realizada a análise de agrupamento por método hierárquico, com distância euclidiana para medir a semelhança entre as variáveis estudadas e o método de Ward como forma de agrupá-las. Nesta análise, as declividades da área com plantio de banana foram agrupadas levando-se em consideração seu grau de semelhança, classificando-as em grupos mais ou menos homogêneos. Observando-se que nos gráficos, as declividades com menor distância euclidiana apresentam maiores semelhanças do que aquelas de maior distanciamento.

O critério estabelecido para a escolha do número de componentes foi adotar aquelas que apresentaram autovalores acima de 1,00 e sintetizaram uma variância acumulada acima de 70\% (Hair Júnior, 2009 \& Freitas et al., 2014). Entretanto, na presente pesquisa esses valores não foram alcançados e, assim, adotou-se a metodologia de Coelho (2003) que tratou do manejo da 
variabilidade espacial e temporal de solos e culturas, concluindo que é possível classificar a significância de valores absolutos encontrados em análises de ACP em: <0,30, classificado como pouco significativo; 0,30-0,40, considerado medianamente significativo; e $\geq 0,50$, tido como altamente significativo. Sendo assim, na presente pesquisa, as variáveis químicas seguiu modelo proposto por Santi el al. (2012) que selecionaram autovetores com peso $\geq 0,50$ (altamente significativo), sendo submetidas a uma nova ACP, que ranquearam o fator solo com maior carga fatorial (escore), selecionado dentro do primeiro componente.

\section{Resultados e Discussão}

\subsection{Análise não-paramétrica}

Na Tabela 1 são apresentados os valores médios dos atributos químicos e da densidade do solo da área cultivada com bananeira e dividida em três declividades com amostragens de solo coletadas em duas profundidades. Dos resultados, pode-se observar que o valor médio significativo foi encontrado nos teores de potássio em ambas as profundidades de amostragem do solo com os maiores valores na parte superior da área e a densidade do solo na camada de 20 a $40 \mathrm{~cm}$ de profundidade na parte mediana da área experimental.

É possível acreditar que os teores de potássio, maiores na parte superior, possam ser devido ao maior acúmulo de biomassa foliar, uma vez que é comum os produtores fazerem a limpeza periódica de folhas secas, sendo estas ricas nesse nutriente, por consequência, incrementando os teores de potássio nessa camada. Outra possibilidade é que o potássio não é metabolizado na planta, formando ligações com moléculas orgânicas de fácil reversibilidade (Rosolem el al., 2007) o que pode explicar, pelo menos em parte, os teores desse elemento na área estudada. Outro ponto a ser observado é que as maiores concentrações de matéria orgânica, também ocorreram na parte superior da área, corroborando os elevados teores desse nutriente. Para as demais análises, não houve diferença significativa pelo teste de Kruskal-Wallis a 5\% de probabilidade. 
Tabela 1. Teste de Kruskal-Wallis ( $\mathrm{P}>0,05)$.

\begin{tabular}{|c|c|c|c|c|}
\hline \multirow{2}{*}{ Variáveis } & \multicolumn{3}{|c|}{ Declividade } & \multirow{2}{*}{$\mathrm{P}$-value } \\
\hline & Superior & Mediano & Inferior & \\
\hline & \multicolumn{4}{|c|}{ Camada de solo $0-20 \mathrm{~cm}$} \\
\hline pH em água & 5,66 & 5,87 & 5,76 & 0,8103 \\
\hline Fósforo disponível $\left(\mathrm{mg} \mathrm{dm}^{-3}\right)$ & 24,28 & 26,35 & 37,32 & 0,8151 \\
\hline Potássio disponível (mg dm $\left.{ }^{-3}\right)$ & 115,07 & 106,47 & 84,39 & 0,0257 \\
\hline Sódio disponível $\left(\mathrm{cmol}_{\mathrm{c}} \mathrm{dm}^{-3}\right)$ & 0,07 & 0,07 & 0,07 & 0,9070 \\
\hline Hidrogênio + alumínio disponível $\left(\mathrm{cmol}_{\mathrm{c}} \mathrm{dm}^{-3}\right)$ & 3,64 & 3,66 & 2,90 & 0,2324 \\
\hline Alumínio disponível $\left(\mathrm{cmol}_{\mathrm{c}} \mathrm{dm}^{-3}\right)$ & 0,27 & 0,21 & 0,26 & 0,5761 \\
\hline Cálcio disponível $\left(\mathrm{cmol}_{\mathrm{c}} \mathrm{dm}^{-3}\right)$ & 2,21 & 2,30 & 2,46 & 0,9069 \\
\hline Magnésio disponível $\left(\mathrm{cmol}_{\mathrm{c}} \mathrm{dm}^{-3}\right)$ & 2,27 & 2,29 & 2,30 & 0,9661 \\
\hline Soma de bases $\left(\mathrm{cmol}_{\mathrm{c}} \mathrm{dm}^{-3}\right)$ & 4,87 & 4,94 & 5,07 & 0,9667 \\
\hline Capacidade de troca catiônica $\left(\mathrm{cmol}_{\mathrm{c}} \mathrm{dm}^{-3}\right)$ & 8,51 & 8,60 & 7,96 & 0,5569 \\
\hline Saturação por bases $(\%)$ & 56,75 & 58,11 & 62,58 & 0,6451 \\
\hline Saturação por alumínio $(\%)$ & 6,04 & 4,24 & 7,07 & 0,5305 \\
\hline Matéria orgânica do solo $\left(\mathrm{g} \mathrm{dm}^{-3}\right)$ & 19,55 & 19,55 & 17,94 & 0,9141 \\
\hline Condutividade elétrica $\left(\mathrm{m} \mathrm{S} \mathrm{m}^{-1}\right)$ & 0,10 & 0,09 & 0,08 & 0,8845 \\
\hline Densidade do solo $\left(\mathrm{g} \mathrm{cm}^{-3}\right)$ & 1,60 & 1,66 & 1,57 & 0,2761 \\
\hline Relação Ca:Mg & 1,26 & 1,63 & 1,28 & 0,9120 \\
\hline Relação $\mathrm{Ca}+\mathrm{Mg}: \mathrm{K}$ & 16,27 & 19,77 & 23,30 & 0,1554 \\
\hline Relação Ca:K & 8,23 & 9,36 & 12,03 & 0,2117 \\
\hline \multirow[t]{2}{*}{ Relação Mg:K } & 8,05 & 10,41 & 11,26 & 0,2766 \\
\hline & \multicolumn{4}{|c|}{ Camada de solo $20-40 \mathrm{~cm}$} \\
\hline pH em água & 5,63 & 5,68 & 5,72 & 0,9989 \\
\hline Fósforo disponível $\left(\mathrm{mg} \mathrm{dm}^{-3}\right)$ & 22,27 & 18,41 & 22,77 & 0,1052 \\
\hline Potássio disponível $\left(\mathrm{mg} \mathrm{dm}^{-3}\right)$ & 107,21 & 79,13 & 77,63 & 0,0485 \\
\hline Sódio disponível $\left(\mathrm{cmol}_{\mathrm{c}} \mathrm{dm}^{-3}\right)$ & 0,06 & 0,05 & 0,07 & 0,8172 \\
\hline Hidrogênio + alumínio disponível $\left(\mathrm{cmol}_{\mathrm{c}} \mathrm{dm}^{-3}\right)$ & 3,58 & 3,49 & 3,37 & 0,7874 \\
\hline Alumínio disponível $\left(\mathrm{cmol}_{\mathrm{c}} \mathrm{dm}^{-3}\right)$ & 0,27 & 0,34 & 0,29 & 0,6687 \\
\hline Cálcio disponível $\left(\mathrm{cmol}_{\mathrm{c}} \mathrm{dm}^{-3}\right)$ & 2,05 & 2,16 & 1,97 & 0,8700 \\
\hline Capacidade de troca catiônica $\left(\mathrm{cmol}_{\mathrm{c}} \mathrm{dm}^{-3}\right)$ & 7,83 & 7,44 & 6,92 & 0,0691 \\
\hline Saturação por bases $(\%)$ & 54,82 & 51,29 & 51,92 & 0,9621 \\
\hline Saturação por alumínio (\%) & 6,38 & 9,64 & 10,55 & 0,7883 \\
\hline Matéria orgânica do solo $\left(\mathrm{g} \mathrm{dm}^{-3}\right)$ & 17,19 & 16,78 & 16,81 & 0,9743 \\
\hline Carbono orgânico total $\left(\mathrm{g} \mathrm{kg}^{-1}\right)$ & 9,97 & 9,74 & 9,75 & 0,9743 \\
\hline Condutividade elétrica ( $\left.\mathrm{m} \mathrm{S} . \mathrm{m}^{-1}\right)$ & 0,09 & 0,08 & 0,07 & 0,4230 \\
\hline Densidade do solo $\left(\mathrm{g} \mathrm{cm}^{-3}\right)$ & 1,65 & 1,69 & 1,63 & 0,0463 \\
\hline Relação Ca:Mg & 1,23 & 1,94 & 1,65 & 0,4254 \\
\hline Relação Ca+Mg:K & 16,08 & 25,40 & 19,35 & 0,1723 \\
\hline Relação Ca:K & 8,48 & 14,46 & 10,96 & 0,1696 \\
\hline Relação Mg:K & 7,60 & 10,94 & 8,39 & 0,5214 \\
\hline
\end{tabular}

Valores médios $( \pm \mathrm{SD}$ ) de pH, P, K, Na, H+Al, Ca, Mg, SB, CTC, v, m, MO, CO, CE, DS, Ca:Mg, Ca+Mg:K, Ca:K e Mg:K sob diferentes declividades do solo manejado com a cultura da bananeira nas camadas do solo de 0-20 e 20-40 cm. Fonte: Autores

\subsection{Análise de agrupamento}

Na Figura 1A observa-se que houve admissão de um corte na distância euclidiana de 5,1. Neste gráfico pode-se admitir a divisão em dois grupos: G1 englobando os dados encontrados na parte inferior da área (IP1) e G2 com os dados encontrados nas partes superior e mediana da área experimental (SP1 e MP1), todos na profundidade de 0-20 cm, respectivamente. Com essa disposição, há a indicação de que, utilizando os atributos químicos, os dados foram ordenados em dois grupos. 
Figura 1. Análise de agrupamentos hierárquica pelo dendrograma para os atributos químico e físico do solo que permite averiguar a similaridade entre as declividades (superior, mediana e inferior) e nas camadas do solo: 0-20 (A) e 20-40 cm (B).
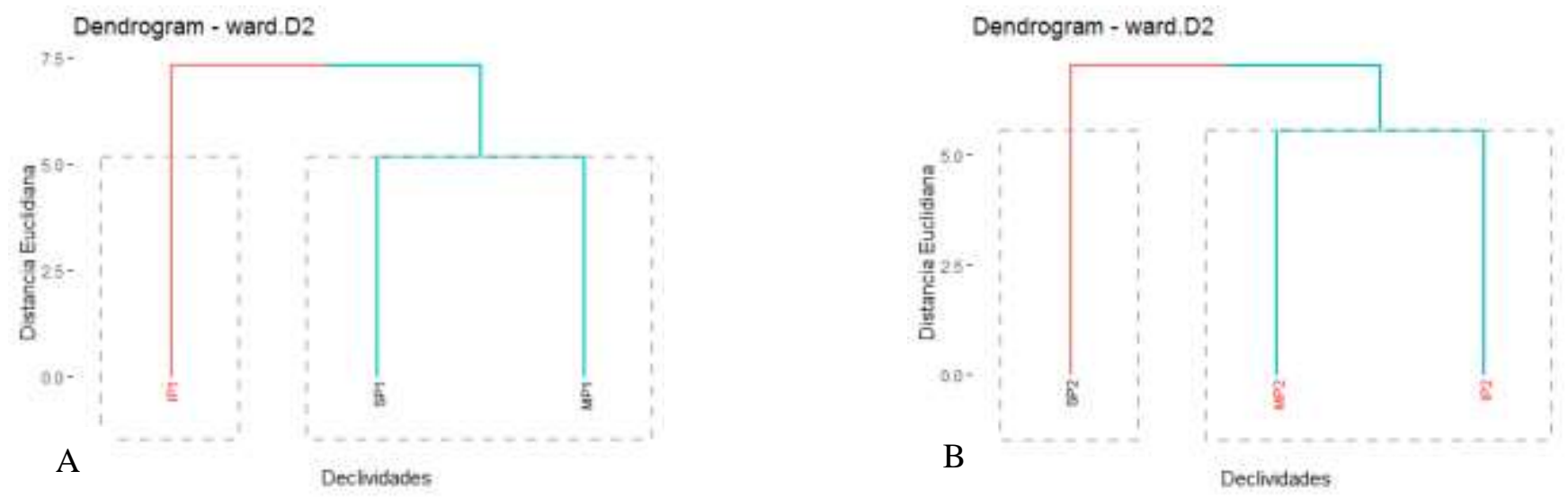

Fonte: Autores.

Na Figura 1B houve um comportamento diferenciado quando os atributos químicos foram agrupados na profundidade de 20-40 cm. Neles foi possível também o agrupamento em dois grupos, sendo o G1 formado pela parte superior em dados coletados no intervalo de 20-40 cm de profundidade (SP2) e o G2, com menor distância euclidiana, as partes mediana e inferior na mesma profundidade (MP2 e IP2). Nestas condições, é possível identificar que, mesmo amostras de solo sendo coletadas em mesma área, os atributos químicos podem variar de acordo com a declividade do terreno, o que está de acordo com Valadares et al. (2008) ao afirmarem que há particularidades em cada ambiente, pois os atributos de um mesmo grupo são semelhantes e diferentes do comportamento de outros agrupamentos (Freitas at al., 2014).

É importante salientar que as partes declivosas dos grupos G2, em ambos os gráficos, é a parte mediana que está sempre presente, possivelmente por ela está intermediando tanto a parte inferior como a superior do terreno trazendo características químicas semelhantes, mas esse comportamento dependeu da profundidade de amostragem do solo. Na profundidade de 0-10 cm esta camada apresentou atributos químicos semelhantes com a camada superior. Já na profundidade de $20-40 \mathrm{~cm}$ a semelhança foi com a camada inferior. Tal fato pode estar relacionado com as concentrações dos nutrientes no perfil do solo e da proximidade entre as camadas, embora tenha sido verificado pequenas variações nos teores dos nutrientes no solo entre as profundidades analisadas.

\subsection{Análise de componentes principais - ACP}

O ajuste do modelo adotado foi capaz de explicar 90,05 e 86,82\% nas camadas de solo de 0-20 cm e 20-40 cm, respectivamente, das variâncias das variáveis que apresentaram autovalores maiores que 1, quando do estudo dos atributos químicos do solo agrupados em quatro fatores (Tabela 2).

Na primeira camada do solo estudada $(0-20 \mathrm{~cm})$, o primeiro componente explicou $39,81 \%$ da variabilidade química do solo da área experimental em sua superfície. Esse componente é constituído pelos teores de hidrogênio + alumínio, alumínio trocável e saturação por alumínio, com escores negativos e, os teores de cálcio, soma de bases, saturação por bases e relações de $\mathrm{Ca}+\mathrm{Mg}: \mathrm{K}$ e $\mathrm{Ca}: \mathrm{K}$, com escores positivos e altamente significativos.

Ainda na Tabela 2 foi possível observar que a proporção acumulada entre o primeiro e o segundo componentes explicou 63,12\% da variabilidade dos dados. Os teores de magnésio, relações Ca:Mg e de $\mathrm{Mg}: \mathrm{K}$, foram os caracteres individuais com maior carga fatorial (escore) selecionados no segundo fator com 0,7833 ; - $-0,7520$ e 0,7761 , respectivamente. 
Tabela 2. Análise de componentes principais das variáveis químicas e física de um solo manejado com a cultura da bananeira sob diferentes declividades em cada camada de coleta do solo.

\begin{tabular}{|c|c|c|c|c|}
\hline \multirow{2}{*}{ Componentes da variância } & \multicolumn{4}{|c|}{ Componentes principais } \\
\hline & 1 & 2 & 3 & 4 \\
\hline & \multicolumn{4}{|c|}{ Camada de solo $0-20 \mathrm{~cm}$} \\
\hline Autovalores $\left(\lambda_{i}\right)$ & 5,18 & 3,03 & 1,96 & 1,54 \\
\hline Percentual (\%) & 39,81 & 23,31 & 15,08 & 11,85 \\
\hline Acumulado (\%) & 39,81 & 63,12 & 78,20 & 90,05 \\
\hline Variáveis & \multicolumn{4}{|c|}{ Correlação com os componentes principais } \\
\hline Hidrogênio + alumínio disponível $\left(\mathrm{cmol}_{\mathrm{c}} \mathrm{dm}^{-3}\right)$ & $-0,5627 *$ & 0,3892 & $-0,3479$ & 0,4288 \\
\hline Alumínio trocável $\left(\mathrm{cmol}_{\mathrm{c}} \mathrm{dm}^{-3}\right)$ & $-0,6904 *$ & 0,4482 & 0,2787 & 0,3532 \\
\hline Cálcio $\left(\mathrm{cmol}_{\mathrm{c}} \mathrm{dm}^{-3}\right)$ & $0,7897 *$ & $-0,4274$ & $-0,0374$ & 0,2870 \\
\hline Magnésio $\left(\mathrm{cmol}_{\mathrm{c}} \mathrm{dm}^{-3}\right)$ & 0,4830 & $0,7833^{*}$ & 0,0563 & $-0,2555$ \\
\hline Soma de bases $\left(\mathrm{cmol}_{\mathrm{c}} \mathrm{dm}^{-3}\right)$ & $0,8848 *$ & 0,2962 & $-0,0127$ & $-0,0237$ \\
\hline Saturação por bases $(\%)$ & $0,8754^{*}$ & $-0,0979$ & 0,2175 & $-0,3288$ \\
\hline Satur & $-0,7670 *$ & 0,2931 & 0,2614 & 0,3510 \\
\hline Matéri & 0,4403 & 0,3924 & $-0,7398 *$ & 0,2320 \\
\hline Carbono orgânico total $\left(\mathrm{g} \mathrm{kg}^{-1}\right)$ & 0,4403 & 0,3924 & $-0,7398 *$ & 0,2320 \\
\hline Relação Ca:Mg & 0,1738 & $-0,7520 *$ & $-0,0387$ & 0,4967 \\
\hline Relação Ca+Mg:K & $0,6367 *$ & 0,3799 & 0,4985 & 0,4016 \\
\hline Relação Ca:K & $0,6684 *$ & $-0,2794$ & 0,3103 & $0,5735^{*}$ \\
\hline Relação Mg:K & 0,3430 & $0,7761 *$ & 0,4480 & 0,0883 \\
\hline \multirow[t]{2}{*}{ Componentes da variância } & 1 & 2 & 3 & 4 \\
\hline & \multicolumn{4}{|c|}{ Camada de solo $20-40 \mathrm{~cm}$} \\
\hline Auto & 4,97 & 2,68 & 2,08 & 1,52 \\
\hline Per & 38,26 & 20,61 & 16,00 & 11,66 \\
\hline Acum & 38,26 & 58,87 & 74,86 & 86,52 \\
\hline Variáveis & \multicolumn{4}{|c|}{ Correlação com os componentes principais } \\
\hline pH em água & $0,6946^{*}$ & 0,4086 & $-0,2413$ & $-0,2577$ \\
\hline Potássio $\left(\mathrm{mg} \mathrm{dm}^{-3}\right)$ & 0,4801 & $-0,7242^{*}$ & $-0,1899$ & $-0,0512$ \\
\hline Hidrogênio + alumínio $\left(\mathrm{cmol}_{\mathrm{c}} \mathrm{dm}^{-3}\right)$ & $-0,6781 *$ & $-0,3992$ & 0,3392 & 0,2043 \\
\hline Alumínio trocável $\left(\mathrm{cmol}_{\mathrm{c}} \mathrm{dm}^{-3}\right)$ & $-0,8871 *$ & $-0,1030$ & $-0,0633$ & 0,1793 \\
\hline Magnésio $\left(\mathrm{cmol}_{\mathrm{c}} \mathrm{dm}^{-3}\right)$ & 0,4828 & $-0,0557$ & $-0,0713$ & $0,8229 *$ \\
\hline Soma de bases $\left(\mathrm{cmol}_{\mathrm{c}} \mathrm{dm}^{-3}\right)$ & $0,8642 *$ & $-0,0199$ & 0,1094 & 0,1932 \\
\hline Saturação por bases (\%) & $0,9104 *$ & 0,2323 & $-0,1558$ & $-0,0495$ \\
\hline Saturação por alumínio (\%) & $-0,9244 *$ & $-0,0256$ & $-0,0209$ & 0,1145 \\
\hline Matéria orgânica do solo $\left(\mathrm{g} \mathrm{dm}^{-3}\right)$ & 0,3963 & $-0,3741$ & $0,7981 *$ & 0,0656 \\
\hline Carbono orgânico total $\left(\mathrm{g} \mathrm{kg}^{-1}\right)$ & 0,3963 & $-0,3741$ & $0,7981 *$ & 0,0656 \\
\hline Relação Ca:Mg & $-0,1234$ & 0,1568 & 0,5080 & $-0,6964 *$ \\
\hline Relação $\mathrm{Ca}+\mathrm{Mg}: \mathrm{K}$ & $-0,1134$ & $0,8532 *$ & 0,3064 & 0,3776 \\
\hline Relação Ca:K & $-0,0899$ & $0,8528 *$ & 0,4455 & 0,0823 \\
\hline \multicolumn{5}{|c|}{$\begin{array}{l}\text { CP1 - primeiro componente principal, } \mathrm{CP} 2 \text { - segundo componente principal; } \mathrm{CP} 3 \text { - terceiro componente } \\
\text { principal; e CP3 - quarto componente principal; } \\
\text { "Caracteres com maiores cargas fatoriais (escores) selecionadas dentro de cada fator. O critério para } \\
\text { classificação foi: valor absoluto <0,30, considerado pouco significativo; } 0,30-0,40 \text {, mediamente } \\
\text { significativo; e } \geq 0,50 \text {, altamente significativo, de acordo com Coelho (2003). } \\
\text { Fonte: Autores. }\end{array}$} \\
\hline
\end{tabular}

O primeiro componente avaliado na camada amostral mais profunda $(20-40 \mathrm{~cm})$, explicou 38,26\% da variabilidade química do solo da área experimental. Esse componente é constituído pelos teores de hidrogênio + alumínio, alumínio trocável, soma de bases e saturação por alumínio, com escores negativos e, os teores de pH em água, soma de bases, com escores positivos e altamente significativos. A proporção acumulada entre o primeiro e o segundo componentes explicou 58,87\% da variabilidade, os teores de potássio, relações $\mathrm{Ca}+\mathrm{Mg}: \mathrm{K}$ e de $\mathrm{Ca}: \mathrm{K}$, foram os caracteres individuais com maior carga fatorial (escore) selecionados dentro do segundo fator, com os seguintes valores encontrados em: - 0,$7242 ; 0,8532$ e 0,8528 , respectivamente.

Coelho (2003) em sua pesquisa, que tratou do manejo da variabilidade espacial e temporal de solos e culturas, concluiu que é possível classificar a significância de valores absolutos encontrados em análises de ACP em: $<0,30$, classificado como pouco significativo; $0,30-0,40$, considerado medianamente significativo; e $\geq 0,50$, tido como altamente significativo. Sendo assim, na presente pesquisa, as variáveis químicas seguiu modelo proposto por Santi el al. (2012) que selecionaram autovetores com peso $\geq 0,50$ (altamente significativo), sendo submetidas a uma nova ACP, que ranquearam o fator solo com maior carga 
fatorial (escore), selecionado dentro do primeiro componente, conforme pode ser visto na Tabela 3.

Tabela 3. Análise de componentes principais que apresentam escore $\geq 0,500$ (positiva ou negativa) com o componente principal 1.

\begin{tabular}{|c|c|c|}
\hline \multirow{2}{*}{ Componentes da variância } & \multicolumn{2}{|c|}{ Componentes principais } \\
\hline & 1 & 2 \\
\hline & \multicolumn{2}{|c|}{ Camada de solo $0-20 \mathrm{~cm}$} \\
\hline Autovalores $\left(\lambda_{\mathrm{i}}\right)$ & 4,68 & 1,50 \\
\hline Percentual (\%) & 58,45 & 18,75 \\
\hline Acumulado (\%) & 58,45 & 77,20 \\
\hline Variáveis & \multicolumn{2}{|c|}{ Correlação com os componentes principais } \\
\hline Hidrogênio + alumínio disponível $\left(\mathrm{cmol}_{\mathrm{c}} \mathrm{dm}^{-3}\right)$ & $-0,6913 *$ & 0,2448 \\
\hline Alumínio disponível $\left(\mathrm{cmol}_{\mathrm{c}} \mathrm{dm}^{-3}\right)$ & $-0,7625 *$ & $0,5551^{*}$ \\
\hline Cálcio disponível $\left(\mathrm{cmol}_{c} \mathrm{dm}^{-3}\right)$ & $0,8447 *$ & 0,1218 \\
\hline Soma de bases $\left(\mathrm{cmol}_{\mathrm{c}} \mathrm{dm}^{-3}\right)$ & $0,7904 *$ & 0,2016 \\
\hline Saturação por bases (\%) & $0,9098 *$ & $-0,0819$ \\
\hline Saturação por alumínio (\%) & $-0,7998 *$ & 0,4836 \\
\hline Relação Ca+Mg:K & $0,5551 *$ & $0,7403 *$ \\
\hline Relação Ca:K & $0,7090 *$ & $0,5367 *$ \\
\hline \multirow[t]{2}{*}{ Componentes da variância } & 1 & 2 \\
\hline & \multicolumn{2}{|c|}{ Camada de solo $20-40 \mathrm{~cm}$} \\
\hline Autovalores $\left(\lambda_{\mathrm{i}}\right)$ & 4,46 & 0,76 \\
\hline Percen & 74,29 & 12,71 \\
\hline Acumulado (\%) & 74,29 & 87,00 \\
\hline Variáveis & \multicolumn{2}{|c|}{ Correlação com os componentes principais } \\
\hline pH em água & $-0,8086^{*}$ & $-0,4181$ \\
\hline Hidrogênio + alumínio disponível $\left(\mathrm{cmol}_{\mathrm{c}} \mathrm{dm}^{-3}\right)$ & $0,7937 *$ & $0,5145^{*}$ \\
\hline Alumínio disponível $\left(\mathrm{cmol}_{\mathrm{c}} \mathrm{dm}^{-3}\right)$ & $0,8958^{*}$ & $-0,1768$ \\
\hline Soma de bases $\left(\mathrm{cmol}_{\mathrm{c}} \mathrm{dm}^{-3}\right)$ & $-0,7975 *$ & 0,4514 \\
\hline Saturação por bases $(\%)$ & $-0,9487^{*}$ & $-0,0428$ \\
\hline Saturação por alumínio $(\%)$ & $0,9138^{*}$ & $-0,2941$ \\
\hline
\end{tabular}

Nesta nova análise, pode-se verificar que a correlação entre as variáveis e as componentes principais possibilitou a classificação das variáveis que mais discriminaram nos teores dos elementos nutritivos em profundidades amostrais do solo sob declividade. A variância explicada pelas componentes principais na profundidade de $0-20 \mathrm{~cm}$, apresenta um percentual de 77,20\% da variância total, sendo 58,45\% na CP1 e 18,75\% na CP2. Na profundidade de $20-40 \mathrm{~cm}$ as CP1 e CP2 responderam por $87,00 \%$ da variância total dos dados originais, onde a CP1 respondeu por $74,29 \%$ e a CP2 por $12,71 \%$. Com isto é possível afirmar que houve redução de dimensionalidade das variáveis originais, com perda da explicação de pouco mais que $20 \%$ nas duas profundidades analisadas (Tabela 3). Valores atribuídos a variabilidade de atributos químicos e físicos com variância acima de 70\% também foram encontrados por Loss et al. (2009) e Freitas (2011).

Nas amostras de solo coletadas na profundidade de 0-20 cm verifica-se que a soma de bases (SB) se correlacionou positivamente com os teores de cálcio (Ca) no solo, saturação por bases (V\%) e relação Ca:K. Por outro lado, com o aumento da soma de bases, saturação por bases e teores de cálcio ocorreu diminuição da acidez trocável $\left(\mathrm{Al}^{+3}\right)$, acidez potencial $\left(\mathrm{H}^{+}+\mathrm{Al}^{+3}\right)$ e saturação por alumínio (m). A medida que a acidez trocável $\left(\mathrm{Al}^{+3}\right)$ aumentou no solo, houve elevação da acidez potencial $\left(\mathrm{H}^{+}+\mathrm{Al}^{+3}\right)$ e saturação por alumínio (m). A relação $\mathrm{Ca}+\mathrm{Mg}: \mathrm{K}$ não se correlacionou com outros atributos químicos do solo (Figura 2A). Possivelmente o maior teor de matéria orgânica presente na camada superior do solo e, consequentemente, a maior CTC, 
pode ter contribuído para a maior retenção de bases, aumento do $\mathrm{pH}$ e diminuição da acidez. A matéria orgânica também apresenta capacidade de complexar o $\mathrm{H}^{+}$e $\mathrm{Al}^{+3}$ presentes na solução do solo (IWATA et al., 2012). A elevação do pH contribui para a diminuição da acidez potencial e acidez trocável que são considerados prejudiciais ao crescimento e desenvolvimento das plantas (Silva et al., 2013).

Em relação a camada do solo de 20 - $40 \mathrm{~cm}$ verifica-se correlação positiva entre a acidez trocável $\left(\mathrm{Al}^{+3}\right)$ e saturação por alumínio e efeito antagônico entre esses atributos do solo e a soma de bases (SB). Observou-se que com o aumento da acidez potencial do solo $\left(\mathrm{H}^{+}+\mathrm{Al}^{+3}\right)$ houve diminuição do $\mathrm{pH}$. $\mathrm{O} \mathrm{pH}$ do solo tendeu a apresentar sinergia com a saturação por bases (V\%) e correlação negativa com a acidez potencial $\left(\mathrm{H}^{+}+\mathrm{Al}^{+3}\right)$ (Figura 2B). Nessa camada do solo ocorreu diminuição dos teores de matéria orgânica e CTC (Tabela 1), o que possivelmente afetou negativamente a retenção de bases e contribuiu para o aumento da acidez potencial e acidez trocável.

Figura 2. Análise de componentes principais (ACP) em função do diagrama de ordenação entre CP1 e CP2 sobre as características do solo manejado com a cultura da bananeira nas camadas de solo de 0-20 (A) e 20-40 cm (B).

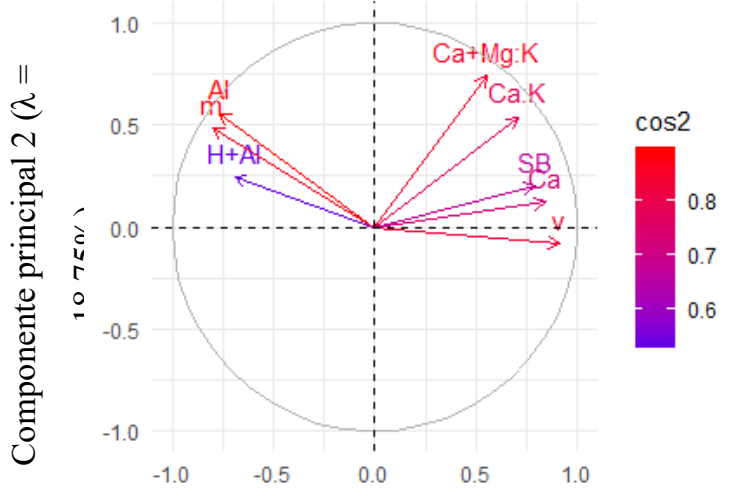

A Componente principal $1(\lambda=58,45 \%)$

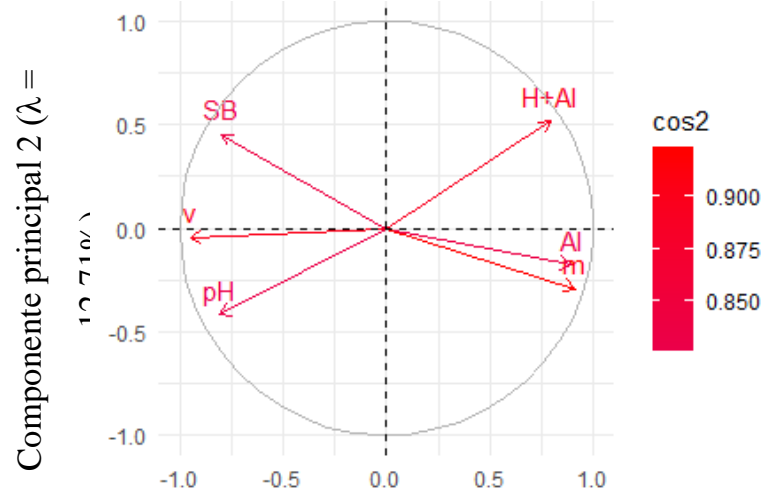

Componente principal $1(\lambda=74,29 \%)$

Fonte: Autores.

Para o agrupamento dos dados foi realizada a média das variáveis que resultaram em grupos distintos para os CP1 e CP2 em relação a declividade da área nas profundidades de 0-20 cm (Figura 3A) e 20-40 cm (Figura 3B). Verificou-se pelos grupos que houve variação dos atributos de fertilidade do solo.

Na camada de $0-20 \mathrm{~cm}$ (Figura 3A), observou-se que a posição inferior se relacionou com os valores mais elevados de $\mathrm{Ca}^{+2}$, soma de bases (SB), saturação por bases (V\%), relação $\mathrm{Ca}: \mathrm{K}$ e relação $\mathrm{Ca}+\mathrm{Mg}: \mathrm{K}$, indicando que houve menor perda da fertilidade do solo nessa posição do relevo. A posição mediana do relevo se relacionou com os maiores valores de acidez trocável $\left(\mathrm{Al}^{3+}\right)$, saturação por alumínio $(\mathrm{m})$ e acidez potencial $\left(\mathrm{H}^{+}+\mathrm{Al}^{+3}\right)$. Já a posição superior do relevo se agrupou na região inferior do diagrama sofrendo pouco influência dos principais atributos químicos do solo. 
Figura 3. Análise de componentes principais (ACP) do diagrama de agrupamento entre os grupos de declividades, inferior (•), mediano $(\boldsymbol{\Delta})$ e superior $(\boldsymbol{\square})$ entre CP1 e CP2 sobre as características do solo manejado com a cultura da bananeira nas camadas de solo de 0-20 (A) e 20-40 cm (B).

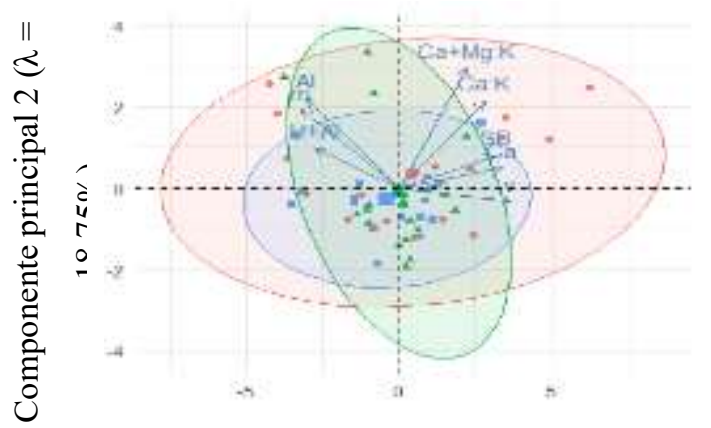

A Componente principal $1(\lambda=58,45 \%)$

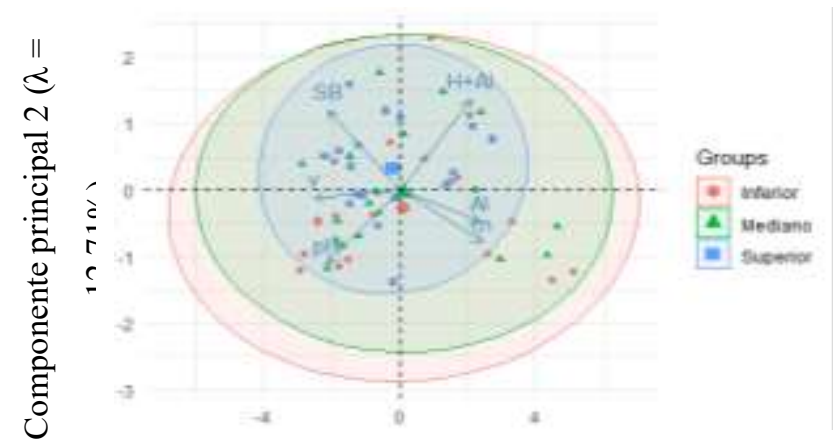

Componente principal $1(\lambda=74,29 \%)$

Fonte: Autores.

Na camada de 20-40 cm (Figura 3B), os grupos representados pela posição inferior e mediana do relevo se relacionaram com os maiores valores de acidez trocável $\left(\mathrm{Al}^{+3}\right)$, e saturação por alumínio (m). Silva et al. (2013) verificaram aumento dos teores de alumínio e saturação por alumínio e diminuição dos valores de $\mathrm{pH}$ e saturação por bases com o aumento da profundidade do solo em um Argissolo Vermelho-Amarelo distrófico.

A posição superior do relevo se relacionou com valores mais elevados de soma de bases e saturação por bases, demostrando que mesmo ocorrendo redução das bases do solo com a profundidade, a posição superior do relevo sofreu menores perdas em relação as demais posições do relevo.

\section{Conclusão}

A maior concentração de matéria orgânica na camada superficial da área experimental contribui para o aumento da capacidade de troca de cátions, retendo bases e aumento do pH com reflexo direto na diminuição da acidez;

Na camada mais profunda do solo $(20-40 \mathrm{~cm})$ houve incremento nos teores de alumínio levando ao aumento da saturação por este elemento, o que levou a diminuição da saturação por bases;

Quanto ao relevo da área experimental, as posições inferior e mediana encontram-se com maiores valores de acidez trocável e saturação por alumínio. Já na posição superior, os valores de soma de bases e saturação por bases são mais elevados com menores perdas e maior incremento dos teores de matéria orgânica devido às folhas de bananeiras depositadas na superfície, atividade comum na região da instalação do experimento;

A utilização de técnicas multivariadas é uma ferramenta de grande utilidade na análise de dados relacionados à atributos químicos do solo com amostras retiradas em diferentes profundidades sob áreas declivosas em sistemas de bananicultura.

\section{Referências}

Alvares, C. A., Stape, J. L., Sentelhas, P. C., Goncalves, J. L. M. de. \& Sparovek, Gerd. (2014). Koppens climate classification map for Brazil. Meteorologische Zeitschrift, 22, 711-728.

Bavoso, M. A., Giarola, N. F. B, Tormena, C. A. \& Pauletti, V. (2010). Preparo do solo em áreas de produção de grãos, silagem e pastejo: efeito na resistência tênsil e friabilidade de agregados. Revista Brasileira de Ciência do Solo, 34

Bilibio, W. D., Corrêa, G. \& F Borges, E. N. (2010). Atributos físicos e químicos de um latossolo, sob diferentes sistemas de cultivo. Revista Ciência e agrotecnologia. 34

Borcahrtt, L. (2013). Atributos físicos e químicos de uma topossequência e ciclagem de nutrientes em áreas de mata nativa e reflorestada. 137f. Tese (Doutorado) - Universidade Federal da Paraíba. Programa de Pós-Graduação em Agronomia - PPGA. 
Brandão, V. S., Cecílio, R. A., Pruski, F. F. \& Silva, D. D. (201k6). Infiltração da Água no Solo. (3a ed.), Ed. UFV. 120p.

Carneiro, M.A.C., Souza, E. D. de, Reisi, E. F. dos., Pereira, H. S. \& Azevedo, W. R. de. (2021). Atributos físicos, químicos e biológicos de solo de cerrado sob diferentes sistemas de uso e manejo. Revista Brasileira de Ciência do Solo, 33:147-157, 2009. http://www.scielo.br/pdf/rbcs/v35n2/v35n2a26.pdf>.

Coelho, A.M. Agricultura de precisão: manejo da variabilidade espacial e temporal dos solos e das culturas. In: Curi, N., Marques, J.J., Guilherme, L.R.G., Lima, J. M. de., Lopes, A.S. \& Alvares V., V. H. (2003). (Ed.). Tópicos em ciência do solo. Viçosa: Sociedade Brasileira de Ciência do Solo, 3, 259-290.

Costa, F. S., Bayer, C., Albuquerque, J. A., \& Fontoura, S. M. V. (2004). Calagem e as propriedades eletroquímicas e físicas de um latossolo em plantio direto. Ciência Rural, 34, 281-284.

Doran, J. W. \& Parkin, T. B. (1994). Defining and assessing soil quality. In: Doran, J.W., Coleman, D.C., Bezdicek, D.F., Stewart, B.A., eds. Defining soil quality for a sustainable environment. Madison, Soil Science Society of America, 3-21. (SSSA Special Publication, 35).

Embrapa Solos - Livro técnico. (2017). Manual de métodos de análise de solo. Embrapa. 573 p.

Faria, V. L., Melloni, R. \& Melloni, E. G. P. (2021) Qualidade do Solo sob Cultivo de Banana em Sistemas de Produção Orgânico e Convencional em Gonçalves (MG). Revista Brasileira de Geografia Física 14, 1206-1219.

Freita, S. L., Casagrande, J, C., Oliveira, I. A. de. \& Campos, M. C. C. (2014). Análise multivariada na avaliação de atributos de solos com diferentes texturas cultivados com cana-de-açúcar. Revista de Ciências Agrárias: Amazonia Journal of Agricultural and Enviromental Sciences. 57, $224-233$.

Gomes, M. A. F. \& FilizolA, H. F. (2006). Indicadores físicos e químicos de qualidade de solo de interesse agrícola. Embrapa Meio Ambiente. Jaguariúna.

Hair Jr., J. F., William, B., Babin, B. \& Anderson, R. E. (2009). Análise multivariada de dados. (6a ed.), Bookman.

Iwata, B. F., Leite, O. F. C., Araújo, A. S. F., Nunes, L. A. P. L., Gehring, C. \& Campos. L. P. (2012). Sistemas agroflorestais e seus efeitos sobre os atributos químicos em Argissolo Vermelho-Amarelo do Cerrado piauiense. Revista Brasileira de Engenharia Agrícola e Ambiental, 16, $730-738$.

Lazzaretti, G., Matsuoka, M., Bettio, I., Paveglio, S. S., Shallemberger, J. B. \& Somavilla, L. (2019). Impacto de diferentes sistemas agrícolas e florestal na qualidade química e biológica do solo de uma propriedade rural. Revista Gestão e sustentabilidade Ambiental, 8, 330-350

Niero, L. A. C., Dechen, S. C. F., Coelho, R. M. \& de Maria, I. C. (2010). Avaliações visuais como índice de qualidade do solo e sua validação por análises físicas e químicas em um Latossolo Vermelho distroférrico com usos e manejos distintos. Revista Brasileira de Ciência do Solo, 34, $1271-1282$.

Rapim. L., Pott. A. C., Volanin. S. J. A., Spliethoff. J., Camilo. L. E., Camilo. L. M. \& Conrado. C. M. A. (2020). Influência do manejo mecânico e da adubação verde nos atributos físicos de Latossolo. Research, Society and Development, 9, e173953258. http://dx.doi.org/10.33448/rsd-v9i5.3258

Rosolem, C. A., Calonego, J. C., Foloni, J. S. S. \& Garcia, R. A. (2007). Potássio lixiviado da palha de aveia-preta e milheto após a dessecação química. Pesquisa Agropecuária Brasileira, 42, 1169-1175

Salviano, A. A. C., Vieira, S. R. \& Sparovek, G. (1998). Variabilidade espacial de atributos de solo e de Crotalaria juncea L. em área severamente erodida. Revista Brasileira de Ciência do Solo, 22

SantoS, J. F., Oliveira, A. P., Alves, A. U., Brito, C. H., Dornelas, C. S. M. \& Nóbrega, J. P. R. (2006). Produção de batata-doce adubada com esterco bovino em solo com baixo teor de matéria orgânica. Horticultura Brasileira, 4, 103-106.

Santi, A. L., Amado, T. J. C., Cherubin, M. R., Martin, T. N. \& Pires, J. L, Flora, L. P. D, C. J, Basso. (2012). Análise de componentes principais de atributos químicos e físicos do solo limitantes à produtividade de grãos. Pesquisa agropecuária brasileira. 47, .1346-1357

Silva, A. S., SILVA, I. F., Ferreira, L. E., Borchartt, L., Souza, M. A. \& Pereira, W. E. (2013). Propriedades físicas e químicas em diferentes usos do solo no Brejo Paraibano. Revista Brasileira de Ciência do Solo, 37, 1064-1072.

Valladares, G. S., Gomes, E. G., Mello, J. C. C. B. S., Pereira, M. G., Anjos, L. H. C., Ebeling, A. G. \& Benites, V. M. (2008). Na análise dos componentes principais e métodos multicritério ordinais no estudo de Organossolos e solos afins. Revista Brasileira de Ciência do Solo, 32, $285-296$. 